\title{
PERANCANGAN APLIKASI PENERIMAAN DAN PENUGASAN PERSONIL PENGAMANAN PT. SIAP ANDALAN PARAMITRA BERBASIS ANDROID
}

\author{
Agus Kodir Arifin \\ Program Studi Informatika, Universitas Indraprasta PGRI \\ agus.arifin@gmail.com
}

\begin{abstract}
Abstrak
Pada saat ini perkembangan teknologi informasi yang semakin meningkat. Salah satu contoh nyata bahwa perkembangan teknologi seperti komputer, smartphone saat ini berperan penting dalam berbagai bidang, salah satunya yaitu bidang penyampaian informasi. PT Siap Andalan Paramitra bergerak di bidang penyedia jasa pengamanan (BUJP) dan sedang menghadapi satu permasalahan yaitu belum adanya penyampaian informasi yang terkoordinasi antara calon pelamar pekerja dan bagian penerimaan karyawan baru. Maka diperlukan suatu sistem penyampaian informasi yang di harapkan mampu mengatasi masalah tersebut. Permasalahan yang dibahas adalah bagaimana langkahlangkah pembuatan Sistem Informasi dengan aplikasi Android. Metode yang digunakan adalah grounded research yaitu suatu metode penelitian berdasarkan pada fakta dan menggunakan analisis perbandingan dengan tujuan mengadakan generalisasi empiris, menetapkan konsep, membuktikan teori, mengembangkan teori, pengumpulan dan analisis data dalam waktu yang bersamaan. Metode ini merupakan usaha untuk mendapatkan penyelesaian dari permasalahan Sistem Informasi Penerimaan dan Penugasan Personil Pengamanan PT. SIAP ANDALAN PARAMITRA.
\end{abstract}

Kata Kunci : Android, Penerimaan karyawan, Informasi

\begin{abstract}
On proof to this present time of development $f$ information technologies the increasing. One of the example was is manifest that develop this kind of technology such as computer, smartphones today plays an important role in various fields, one of which is the field of information delivery. PT Ready Main Paramitra is engaged in security service provider (BUJP) and is facing one problem, namely the lack of coordinated information delivery between prospective job applicants and new employee admissions. Then we need a system of information delivery that is expected to be able to overcome the problem. The problem discussed is how to make the Information System with an Android application. The method used is grounded research, which is a research method based on facts and uses comparative analysis with the aim of holding empirical generalizations, defining concepts, proving theories, developing theories, collecting and analyzing data at the same time. This method is an attempt to get a solution to the problem of Information Systems Acceptance and Assignment of Security Personnel PT. Ready Main Paramitra
\end{abstract}

Keywords: Androd, employess, information

\section{PENDAHULUAN}

Saat ini berkembangnya teknologi informasi yang semakin meningkat. Merupakan wujud nyata yaitu bahwa perkembangan teknologi seperti komputer, smartphone saat ini mempunyai efek besar dalam berbagai bidang, salah satunya yaitu bidang penyampaian informasi. PT Siap Andalan Paramitra bergerak di bidang penyedia jasa pengamanan (BUJP) dan sedang menghadapi satu permasalahan yaitu belum adanya penyampaian informasi yang terkoordinasi antara calon pelamar pekerja dan bagian penerimaan karyawan baru. Maka diperlukan suatu sistem penyampaian informasi yang di harapkan mampu mengatasi masalah- 
masalah yang timbul, khususnya pada bagian penerimaan karyawan baru.

Berdasarkan pada identifikasi masalah yaitu :

1. Bagian penerimaan tidak dapat mengontrol dokumen pelamar yang sudah dipanggil dan yang belum dipanggil sehingga informasi yang disampaikan ke pelamar sering kali tidak sesuai dengan data yang ada.

2. Laporan ke pimpinan tentang data lamaran sering kali tidak akurat.

3. Waktu yang diperlukan dalam mencari data seperti lamaran yang diterima sudah dipanggil, lamaran ditolak, lamaran yang belum dipanggil relative lama

Adapun rumusan masalah:

1. Apakah proses penerimaan dan penugasan yang dilakukan saat ini sudah efektif?

2. Apakah pemantauan proses pemanggilan pelamar sudah cukup baik sehingga tidak ada pemanggilan lebih dari satu kali atau berulang?

3. Apakah sistem Penerimaan dan Penugasan Personil Pengamanan dapat mengkoordinir semua data informasi yang ada?

4. Apakah sistem Penerimaan dan Penugasan Personil Pengamanan membatasi akses user dalam mengolah data pelamar?

5. Apakah sistem Penerimaan dan Penugasan Personil Pengamanan dapat menghemat pembiayaan alat pendukung aplikasi?

6. Apakah sistem Penerimaan dan Penugasan Personil Pengamanan dapat mempercepat proses penerimaan karyawan baru pada PT Siap Andalan Paramitra
Tujuan dari penelitian tersebut adalah :

1. Untuk mengetahui dan memudahkan bagian penerimaan karyawan baru melakukan penerimaan dan pemrosesan data pelamar

2. Untuk mengidentifikasikan masalah berikutnya bisa dilakukan dengan mudah dan lebih hemat biaya.

3. Memberikan fleksibiltas proses penerimaan dan penugasan personil pengamanan.

4. Untuk mengurangi beban Perusahaan saat penerimaan personil pengamanan baru.

5. Memberikan informasi sampai dimana proses dari aplikasi lamaran kepada calon pegawai/ pelamar baru.

6. Memudahkan petugas pengamanan yang telah di terima untuk melihat informasi penugasan dan nomor telepon atasan/ supervisor di tempat penugasanan pengamanan

Kegunaan Penelitian tersebut adalah :

a. Untuk dapat mengoptimalkan kinerja pada perusahaan khususnya dalam penerimaan dan penugasan karyawan baru.

b. Diharapkan penulis dapat memperbarui sistem yang bermula masih menggunakan microsoft office excel, menjadi sebuah sistem yang lebih cepat, modern dan lebih mudah dalam penggunaanya.

c. Sebagai pertimbangan dan masukan kepada perusahaan mengenai sistem informasi manajemen yang dapat dijadikan sebagai sistem pendukung keputusan dan mempermudah pemantauan terhadap transaksi yang ada secara mandiri dimanapun dan kapanpun. 


\section{Konsep Dasar Sistem}

Pengertian sistem menurut beberapa ahli yaitu, sistem adalah sebuah kelompok dari dua atau lebih komponen yang saling berhubungan atau subsistem untuk mencapai tujuan bersama. Dari definisi diatas, dapat disimpulkan bahwa sistem adalah komponen komponen yang saling berkaitan dan bekerjasama untuk mencapai suatu tujuan tertentu [1] yang menjelaskan hubungan antara data dan informasi. Informasi adalah data yang telah diproses ke dalam suatu bentuk yang mempunyai arti bagi si penerima dan mempunyai nilai nyata dan terasa bagi keputusan saat itu atau keputusan mendatang [7]. Data adalah fakta dari suatu pernyataan yang berasal dari kenyataan, dimana pernyataan tersebut merupakan hasil pengukuran atau pengamatan [8]. Sistem informasi adalah kumpulan dari sub-sub sistem baik phisik maupun non phisik yang saling berhubungan, satu sama lain dan bekerja sama secara harmonis untuk mencapai satu tujuan yaitu mengolah data menjadi informasi yang berguna [2]. Sistem informasi merupakan kumpulan dari perangkat keras dan perangkat lunak komputer serta perangkat manusia yang akan mengolah data menggunakan perangkat keras dan perangkat lunak tersebut.

Software adalah program komputer yang terasosiasi dengan dokumentasi perangkat lunak seperti dokumentasi kebutuhan, model desain, dan cara penggunaan (user manual) [6].

Android merupakan sistem operasi untuk telepon seluler yang berbasis Linux. Android menyediakan platform terbuka bagi para pengembang untuk menciptakan aplikasi mereka sendiri untuk digunakan oleh bermacam peranti bergerak. Android umum digunakan di smartphone dan juga tablet PC. Fungsinya sama seperti sistem operasi Symbian di Nokia, iOS di Apple dan BlackBerry OS[5].

Penarikan (recruitment) adalah masalah penting dalam pengadaan tenaga kerja. Jika penarikan berhasil artinya bnyak pelamar yang memasukkan lamarannya, peluang untuk mendapatkan karyawan yang baik terbuka lebar, karena perusahaan dapat memilih yang terbaik diantara yang baik [3]. Sedangkan diartikan sebagai suatu proses untuk mendapatkan calon karyawan yang memiliki kemampuan yang sesuai dengan kualifikasi dan kebutuhan suatu organisasi/perusahaan[4].

Berdasarkan dari beberapa pengertian di atas dapat disimpulkan bahwa Rekrutmen adalah usaha mencari, menemukan, menarik dan mempengaruhi tenaga kerja agar melamar lowongan pekerjaan yang ada dalam suatu perusahaan.

\section{METODE PENELITIAN}

Metode penelitian yang diterapkan dalam penelitian ini adalah metode grounded research yaitu suatu metode penelitian berdasarkan pada fakta dan menggunakan analisis perbandingan dengan tujuan mengadakan generalisasi empiris, menetapkan konsep, membuktikan teori, mengembangkan teori, pengumpulan dan analisis data dalam waktu yang bersamaan. Setelah mengumpulkan data, penulis melanjutkan proses penelitian sesuai dengan langkah-langkah pokok yang digunakan pada metode ini, yaitu menentukan masalah yang ingin diselidiki, mengumpulkan data atau informasi yang ada di lapangan, menganalisis dan menjelaskan masalah yang ditemukan serta membuat laporan hasil penelitian. 


\section{Langkah-langkah Sistem \\ Pengembangan}

\section{Analisa Kebutuhan Sistem}

Analisa kebutuhan berguna untuk mendapatkan data-data yang diterapkan sebagai masukkan dari suatu sistem dan mengolah data yang berhubungan dengan tugas akhir ini. Proses perancangan aplikasi penerimaan \& penugasan personil pengamanan perusahaan dimulai dari memahami pengguna. Sebelum merancang sebuah sistem kita harus memahami kebutuhan pengguna, apa saja yang pengguna inginkan. Step-step yang dilakukan pada tahap ini adalah :

a. Menentukan profil pengguna.

b. Menganalisa task-task yang digunakan.

c. Menganalisa data masukan.

d. Menganalisis proses yang berjalan atau proses yang digunakan.

e. Mengumpulkan kebutuhankebutuhan pengguna.

f. Menyamakan kebutuhan tersebut dengan task.

\section{Studi Kepustakaan}

Penulis melakukan beberapa kajian literature berdasarkan referensi dan berbagai riset dan juga wawancara dengan orang yang ahli pada kasus ini. Kajian lteratur ini berguna untuk mendalami dan mengerti tentang dasar yang terkait dengan kebutuhan yang telah dilakukan.

\section{Perancangan sistem}

Bertujuan untuk merancang sistem yang akan dibuat agar dapat diimplementasikan dengan kebutuhan pengguna. Urutanurutan yang dilakukan dalam perancangan aplikasi penerimaan $\&$ penugasan personil pengamanan ini adalah :

a. Merancang database

Dalam merancang sistem database digunakan untuk mensave data-data yang telah diinput atau dimasukkan. Langkah yang dilakukan dalam mendesain database adalah:

1) Membuat tabel-tabel data dan juga primary key-nya,

2) Menentukan relationship dari setiap tabel,

3) Membuat query,

4) Membuat report yang digunakan untuk menampilkan hasil output sebelum dicetak,

5) Membuat normalisasi bila terdapat tabel data yang unnormal.

b. Merancang antarmuka

Dalam merancang antarmuka atau tampilan ada beberapa hal yang harus diperhatikan oleh perancang tampilan, yaitu :

1) Harus memiliki jiwa seni,

2) Mengerti selera pengguna secara umum,

3) Melakukan dokumentasi rancangan agar rancangan dapat diubah dengan cara :

a) Membuat sketsa pada kertas,

b) Menggunakan peranti prototype,

c) Penjelasan keterkaitan jendela satu dengan yang lainnya, dan

d) Menggunakan peranti bantu.

Selain itu, dalam tahap desain antarmuka ada sistematis tahapan yang harus dilalui, yaitu :

1) Merancang menu utama beserta icon objek, views, dan representasi visual,

2) Merancang form untuk memasukkan dan menyimpan data,

3) Merancang tampilan untuk hasil output-nya,

4) Merancang form untuk pencarian data.

c. Mengembangkan antarmuka

Dalam melakukan pengembangan terhadap antarmuka, hal pertama 
yang harus kita perhatikan adalah membangun prototype. Membangun prototype adalah cara yang berharga dalam membuat rancangan awal dan membuat demonstrasi, maka sangat penting untuk melakukan pengujian kegunaan antarmuka. Dari prototype tersebut, perancang antarmuka dapat mulai membangun antarmuka secara utuh. Ketika membuat prototype, sangat penting untuk diingat bahwa prototype harus dapat dibuang setelah digunakan (disposable), dimana tujuan dalam membuat prototype adalah untuk mempercepat dan mempermudah dalam memvisualisasikan desain alternatif dan konsep, bukan untuk membangun kode yang akan digunakan sebagai bagian dari produk.

d. Melakukan validasi terhadap antarmuka

Evaluasi kegunaan adalah bagian penting dari proses pengembangan, untuk mengetahui bagaimana tanggapan pengguna terhadap antarmuka yang telah dibuat. Evaluasi ini akan kita gunakan untuk memperbaiki kekurangan pada antarmuka yang telah terbangun. Aturan dalam perancangan antarmuka adalah :

1) Buatlah antarmuka yang mudah dipahami dan dikuasai oleh pengguna,

2) Buatlah antarmuka yang konsisten.

\section{Implementasi dan Pengkodean}

Implementasi atau pengkodean adalah proses menerjemahkan dokumen hasil desain menjadi baris-baris perintah bahasa pemrograman komputer, yang selanjutnya dibangun buku manual atau pedoman sebagai acuan informasi untuk user yang akan menggunakan aplikasi atau sistem. Semakin baik hasil analisa dan desain yang dilakukan, maka proses pengkodean ini akan lebih mudah dilakukan.

Tahap implementasi yang dilakukan oleh peneliti terdiri dari langkah-langkah sebagai berikut ini :

a. Menerapkan rencana implementasi Rencana implementasi dimaksudkan terutama untuk mengatur biaya dan waktu yang dibutuhkan selama implementasi. Dalam rencana implementasi ini, semua biaya yang akan dikeluarkan untuk kegiatan implementasi perlu dianggarkan dalam bentuk anggaran biaya. Anggaran biaya ini selanjutnya juga berfungsi sebagai pengendalian terhadap biaya-biaya yang harus dikeluarkan. Waktu yang diperlukan untuk melakukan kegiatan juga perlu diatur dalam rencana implementasi dalam bentuk schedul waktu. Schedul waktu berfungsi sebagai pengendalian terhadap waktu implementasi.

b. Melakukan kegiatan implementasi

- Pemilihan dan pelatihan personil

- Pemilihan tempat dan instalasi perangkat keras dan perangkat lunak

- Pemrograman dan pengetesan program

- Pengetesan sistem

- Konversi system

c. Tindak lanjut implementasi

Penulis masih perlu melakukan tindak lanjut berikutnya setelah sistem baru diimplementasikan. Penulis masih perlu melakukan pengetesan penerimaan sistem. Pengetesan ini berbeda dengan pengetesan sistem yang telah 
dilakukan sebelumnya. Pada pengetesan ini dilakukan dengan menggunakan data sesungguhnya dalam jangka waktu tertentu yang dilakukan oleh penulis bersamasama dengan user.

\section{Pengujian Sistem}

Pengujian adalah proses eksekusi program untuk menemukan kesalahan dan juga untuk memastikan apakah semua fungsi sistem bekerja dengan baik, dan mencari apakah masih ada kesalahan pada sistem. Pengujian sangat penting untuk dilakukan untuk mendapatkan sistem yang benar-benar valid dan sesuai dengan kebutuhan yang sudah dideskripsikan serta menjamin kualitas software, dan juga menjadi peninjauan terakhir terhadap spesifikasi, desain, dan pengkodean. Pengujian yang sukses adalah pengujian yang dapat menyingkapkan kesalahan-kesalahan yang belum terdeteksi

\section{Mengambil Keputusan}

a. Apakah fungsi yang terdapat pada perancangan aplikasi penerimaan \& penugasan personil pengamanan PT. Siap Andalan Paramitra sudah dapat berfungsi sebagaimana yang dimaksud.

b. Apakah aplikasi yang dibuat sudah dapat memenuhi kebutuhan untuk suatu perancangan aplikasi penerimaan \& penugasan personil pengamanan perusahaan.

\section{HASIL DAN PEMBAHASAN}

Aturan bisnis sistem untuk penerimaan dan penugasan personil pengamanan di PT SIAP Andalan Paramitra yang diusulkan:
1. Pelamar yang ingin bergabung dengan PT SIAP Andalan Paramitra menyerahkan berkas lamaran secara langsung ke kantor head office.

2. Petugas bagian penerimaan dan penempatan personil pengamanan akan melihat berkas lamaran dan melakukan pemeriksaan fisik dasar seperti tinggi dan berat badan.

3. Jika berkas lengkap dan tes fisik dasar memenuhi kualifikasi maka bagian penerimaan dan penempatan personil pengamanan akan memberikan kode pelamar pada pelamar tersebut untuk isi form biodata yang disediakan.

4. Pelamar diarahkan untuk mengunduh aplikasi Penerimaan dan Penugasan Personil Pengamanan PT SIAP Andalan Paramitra di playstore.

5. Pelamar akan mengecek status lamaran via aplikasi tersebut.

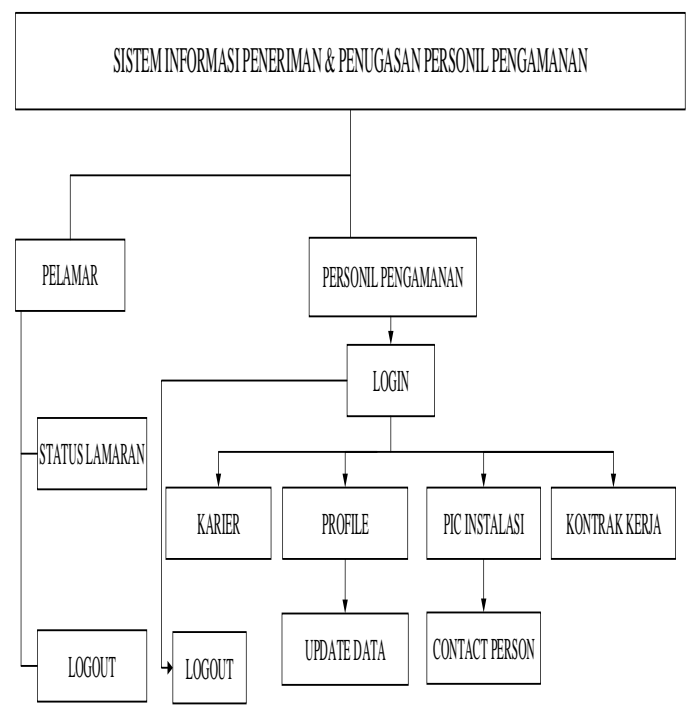

Gambar 1. Dekomposisi Fungsi Sistem 

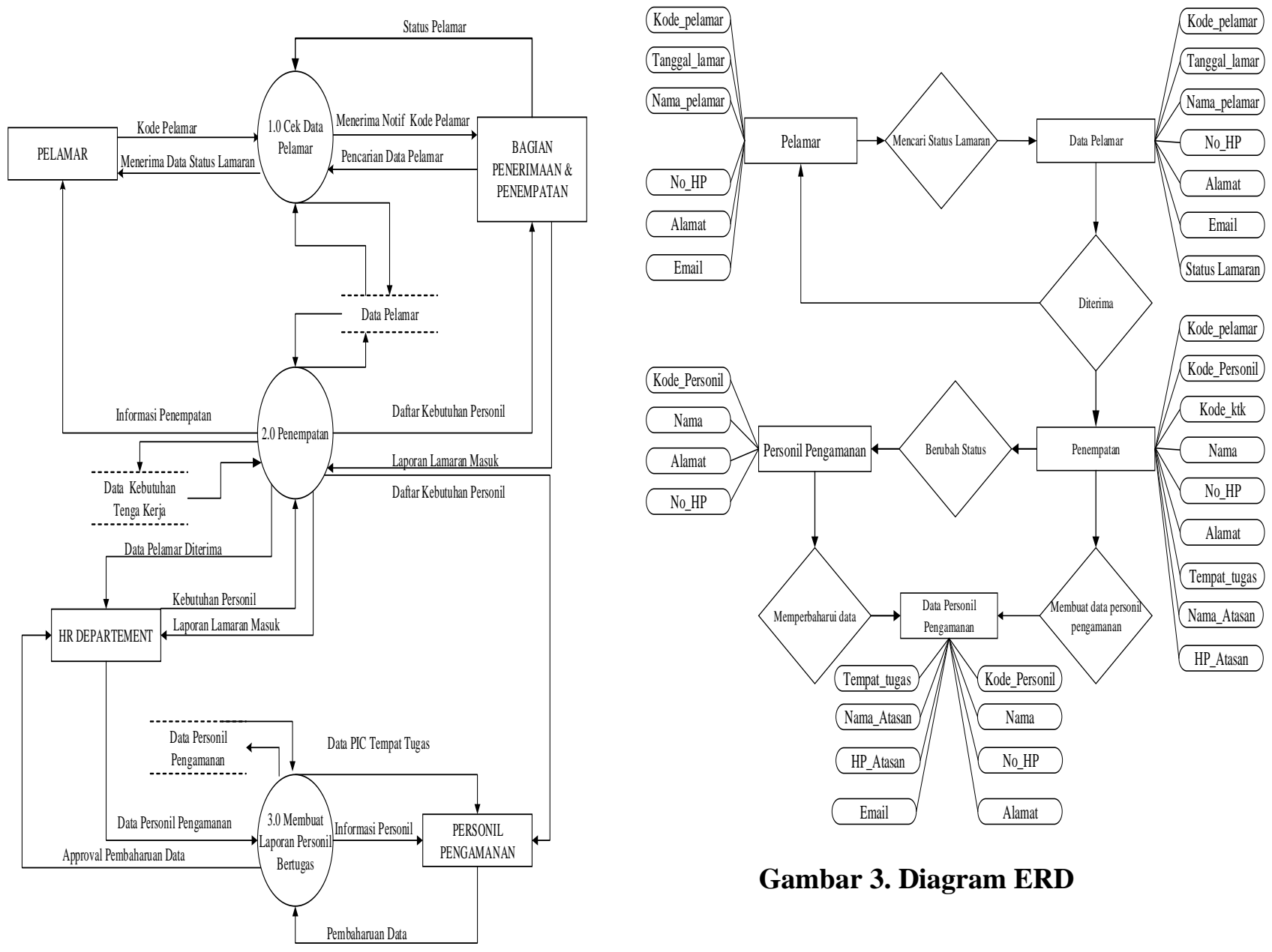

Gambar 3. Diagram ERD

Gambar 2. Diagram Kontek 


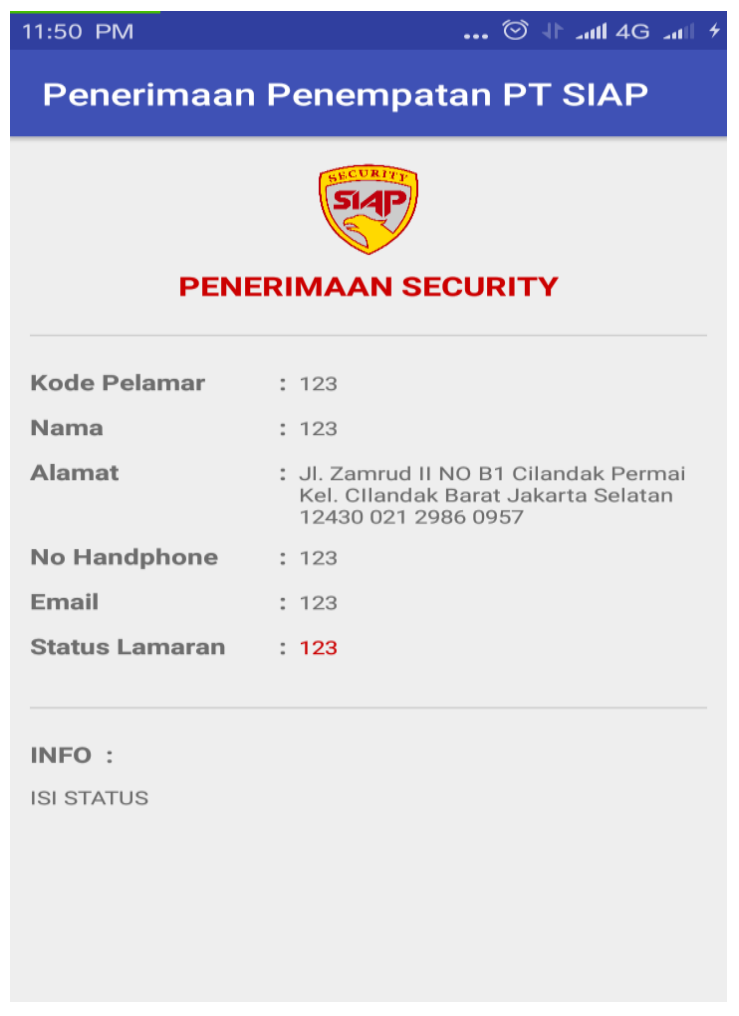

Gambar 4. Tampilan Aplikasi Penerimaan

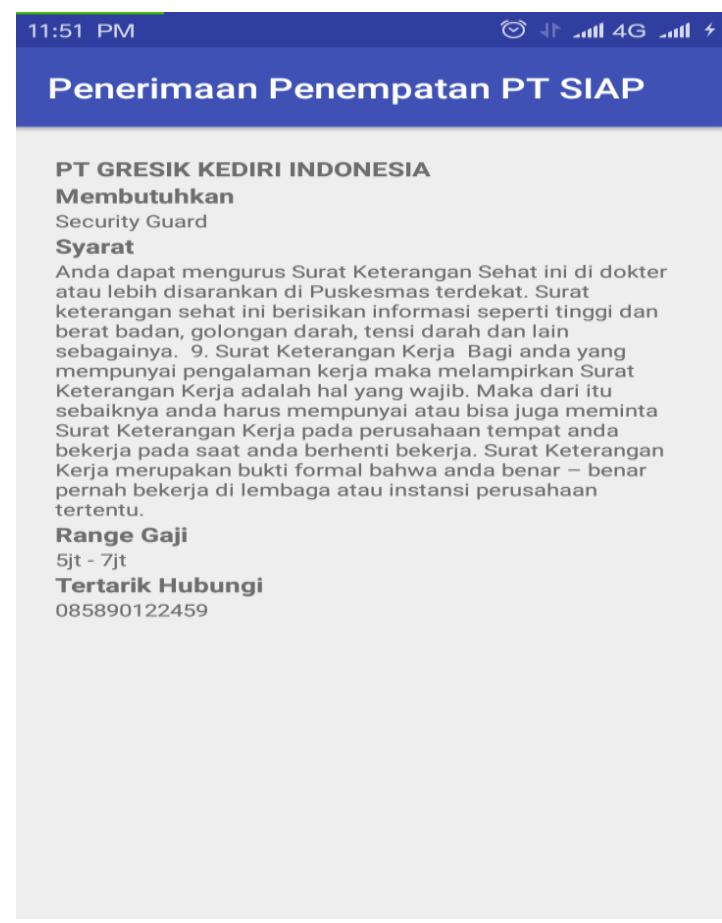

Gambar 5. Tampilan Aplikasi Informasi

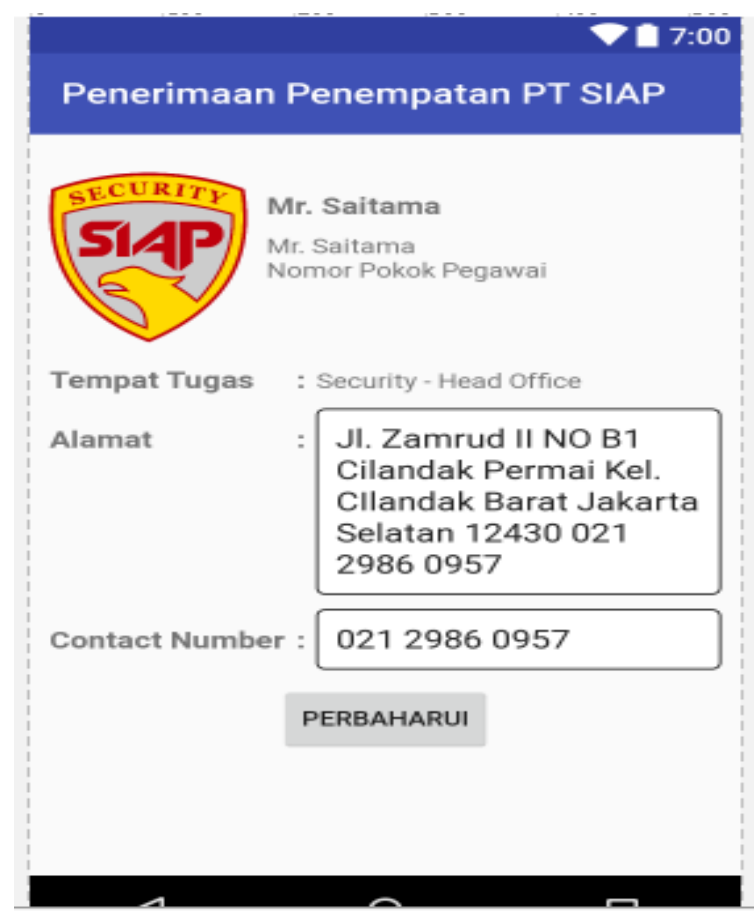

\section{Gambar 6. Tampilan Aplikasi Penugasan Karyawan}

\section{SIMPULAN}

Dengan dibuatnya Aplikasi Penerimaan dan Penugasan Personil Pengamanan PT SIAP Andalan Paramitra semua kegiatan penerimaan dan penempatan dapat berjalan dengan baik, pada aplikasi ini bagian penerimaan dan penempatan dapat menanganani pekerjaan pemanggilan seleksi dan menginformasikan hasil seleksi dengan mudah. Dengan adanya aplikasi ini diharapkan akan mempermudah kegiatan atau aktivasi pekerjaan yang memerlukan kecepatan dan ketepatan informasi.. Dengan adanya perangkat komputer sebagai alat bantu penginputan dan smartphone android sebagai penerima informasi, penulis mempunyai kesimpulan dengan menggunakan sistem ini berdasarkan perumusahan masalah sebagai berikut : 
1. Rancangan Aplikasi Penerimaan dan Penugasan Personil Pengamanan PT SIAP Andalan Paramitra lebih efektif dan up to datedalam pengolahan data daripada sistem sebelumnya.

2. Rancangan Aplikasi Penerimaan dan Penugasan Personil Pengamanan PT SIAP Andalan Paramitra mampu menginformasikan perkembangan status pelamar pada saat proses penerimaan.

3. Rancangan Aplikasi Penerimaan dan Penugasan Personil Pengamanan PT SIAP Andalan Paramitra mampu menghasilkan informasi tentang penempatan personil pengamanan sehingga membantu personil pengamanan lebih efektif dalam proses penempatan.

4. Rancangan Aplikasi Penerimaan dan Penugasan Personil Pengamanan PT SIAP Andalan Paramitra mampu membantu pihak perusahaan mendapatkan laporan atau informasi mengenai status penerimaan dan komposisi petugas pengamanan yang ditempatkan di masing-masing site.

Dengan diterapkannya Aplikasi

Penerimaan dan Penugasan Personil Pengamanan pada PT SIAP Andalan Paramitra yang berbasis Android merupakan salah satu langkah maju dalam penerapan teknologi informasi.

\section{Saran}

Sejalan dengan sistem yang diusulkan oleh penulis, disaran sebagai berikut :

1. Aplikasi Penerimaan dan Penugasan Personil Pengamanan pada PT SIAP Andalan Paramitra diharapkan dapat dilakukan perawatan secara berkala dan pembaharuan yang dicocokan dengan keadaan saat ini.

2. Aplikasi Penerimaan dan Penugasan Personil Pengamanan pada PT SIAP Andalan Paramitra agar diinformasikan dan disosialisasikan pada seluruh pengguna Aplikasi.

3. Aplikasi Penerimaan dan Penugasan Personil Pengamanan pada PT SIAP Andalan Paramitra bisa dikembangkan tidak terbatas hanya pada smartphone android namun bisa digunakan pada multiplatformoperating sistem lainnya.

\section{DAFTAR PUSTAKA}

[1] A Hall, James. Sistem Informasi Akuntansi, Edisi 4, Jakarta:Salemba Empat. 2011.

[2] Azhar Susanto. Sistem Informasi Akuntansi. Bandung: Lingga Jaya. 2013.

[3] Hasibuan, Malayu S.P. Manajemen SDM. Jakarta: PT Bumi Aksara. 2010.

[4] Mardiyanto, A. Recruitment Handbook: Panduan Praktis untuk Melakukan Rekrutmen dan Seleksi. Sukoharjo: Insight Solusi Mandiri. 2009.

[5] Nazarudin Safaat Harahap. Pemograman Aplikasi Mobile Smartphone dan Tablet PC Berbasis Android. Informatika. Bandung. 2012.

[6] Sukamto, Rosa A. dan M. Salahuddin. 2014. Rekayasa Perangkat Lunak Terstruktur dan Berorientasi Objek. Bandung: Informatika.

[7] Sutabri, Tata. 2012. Analisis Sistem Informasi. Yogyakarta: Andi.

[8] Sutarman, Pengantar Teknologi Informasi, Jakarta: Bumi Aksara, 2012. 